NASA/TM-2001-210699

AIAA-2001-0661

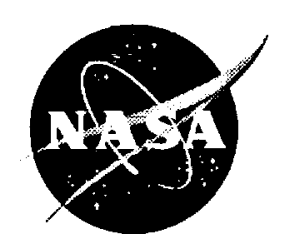

\title{
Fan Noise Reduction: An Overview
}

Edmane Envia

Glenn Research Center, Cleveland, Ohio 
Since its founding, NASA has been dedicated to the advancement of aeronautics and space science. The NASA Scientific and Technical Information (STI) Program Office plays a key part in helping NASA maintain this important role.

The NASA STI Program Office is operated by Langley Research Center, the Lead Center for NASA's scientific and technical information. The NASA STI Program Office provides access to the NASA STI Database, the largest collection of aeronautical and space science STI in the world. The Program Office is also NASA's institutional mechanism for disseminating the results of its research and development activities. These results are published by NASA in the NASA STI Report Series, which includes the following report types:

- TECHNICAL PUBLICATION. Reports of completed research or a major significant phase of research that present the results of NASA programs and include extensive data or theoretical analysis. Includes compilations of significant scientific and technical data and information deemed to be of continuing reference value. NASA's counterpart of peerreviewed formal professional papers but has less stringent limitations on manuscript length and extent of graphic presentations.

- TECHNICAL MEMORANDUM. Scientific and technical findings that are preliminary or of specialized interest, e.g., quick release reports, working papers, and bibliographies that contain minimal annotation. Does not contain extensive analysis.

- CONTRACTOR REPORT. Scientific and technical findings by NASA-sponsored contractors and grantees.
- CONFERENCE PUBLICATION. Collected papers from scientific and technical conferences, symposia, seminars, or other meetings sponsored or cosponsored by NASA.

- SPECIAL PUBLICATION. Scientific, technical, or historical information from NASA programs, projects, and missions, often concerned with subjects having substantial public interest.

- TECHNICAL TRANSLATION. Englishlanguage translations of foreign scientific and technical material pertinent to NASA's mission.

Specialized services that complement the STI Program Office's diverse offerings include creating custom thesauri, building customized data bases, organizing and publishing research results... even providing videos.

For more information about the NASA STI Program Office, see the following:

- Access the NASA STI Program Home Page at http://www.sti.nasa.gov

- E-mail your question via the Internet to help@sti.nasa.gov

- Fax your question to the NASA Access Help Desk at 301-621-0134

- Telephone the NASA Access Help Desk at 301-621-0390

- Write to:

NASA Access Help Desk NASA Center for AeroSpace Information 7121 Standard Drive Hanover, MD 21076 
NASA/TM-2001-210699

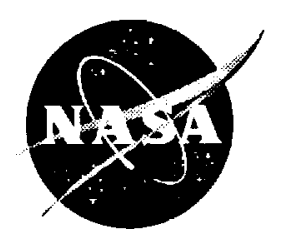

\section{Fan Noise Reduction: An Overview}

Edmane Envia

Glenn Research Center, Cleveland, Ohio

Prepared for the

39 th Aerospace Sciences Meeting and Exhibit

sponsored by the American Institute of Aeronautics and Astronautics

Reno, Nevada, January 8-11, 2001

National Aeronautics and

Space Administration

Glenn Research Center 
Available from

NASA Center for Aerospace Information 7121 Standard Drive

Hanover, MD 21076

Price Code: A03
National Technical Information Service 5285 Port Royal Road Springfield, VA 22100

Available electronically at http://gltrs.grc.nasa.gov/GLTRS 


\title{
FAN NOISE REDUCTION: AN OVERVIEW
}

\author{
Edmane Envia" \\ National Aeronautics and Space Administration \\ Glenn Research Center \\ Cleveland, Ohio 44135
}

\begin{abstract}
Fan noise reduction technologies developed as part of the engine noise reduction element of the Advanced Subsonic Technology Program are reviewed. Developments in low-noise fan stage design, swept and leaned outlet guide vanes, active noise control, fan flow management, and scarfed inlet are discussed. In each case, a description of the method is presented and, where available, representative results and general conclusions are discussed. The review concludes with a summary of the accomplishments of the AST-sponsored fan noise reduction research and a few thoughts on future work.
\end{abstract}

\section{INTRODUCTION}

With the advent of high bypass ratio turbofan engines, the fan has become a major source of modern commercial aircraft propulsion noise. In fact, engine system noise studies [1] indicate that, at both takeoff and approach operations the fan noise tends to dominate the engine total flyover noise signature even when noisc suppression due to acoustic liners is included (sce Fig. 1). The anticipated growth in the engine bypass ratio is likely to increase the importance of the fan noise even further. Therefore, any significant reduction in the level of noise produced by modern aircraft power plants must include provisions for controlling and reducing the fan noise.

The early work in the area of fan noise reduction developed along two distinct lines: (I) noise source control and (2) noise level reduction. Examples of source control methods include, blade-vane count selections to achieve "cut-off" of the rotor-stator interaction tone noise caused by the fan wakes impinging on the core inlet and bypass outlet guide vanes, rotor-stator spacing optimization to weaken the impinging wakes, clean inlet designs to minimize inflow distortions ingested by the fan, and minimizing the potential pressure fields from engine struts and pylons in which the fan has to operate. The noise reduction methods on the other hand have mainly involved the use of inlet and exhaust fan duct acoustic liners to absorb the noise radiated by the various fan sources. However, while, for the most part, these methods have proven effective, they have also tended to suffer from inherent limitations. For example, the cut-off method is primarily used to eliminate rotorstator tone noise at the blade passing frequency (BPF), since the blade-vane counts required for cutting off the higher harmonics of the BPF are usually not practical. Similarly, the rotor-stator spacing optimization method is always constrained by the size and weight penalties associated with increasing the engine length. As for the

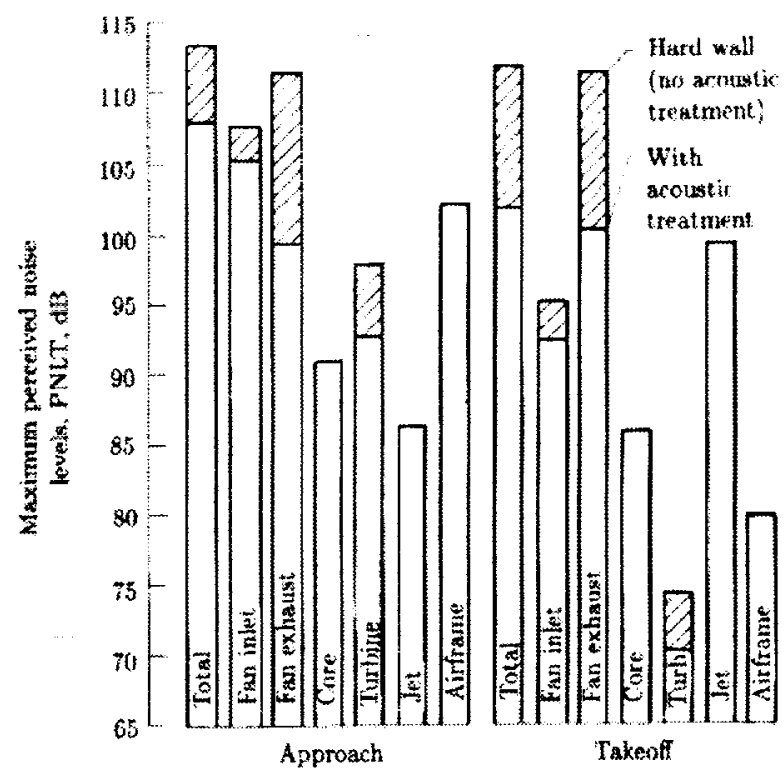

Figure 1. Representative high bypass ratio turbofan engine flyover noise levels on a component basis. Figure reproduced from Ref. 1 .

*Aerospace Engineer, Senior Member, AIAA. 
liners, their effectiveness is likely to diminish as engine bypass ratio is increased. This is mainly due to the fact that an increase in the bypass ratio is usually accompanied by a decrease in the nacelle length and thickness and, hence, a decrease in the available treatment area [2]. Less treatment area means less noise reduction benefits from liners.

To circumvent these limitations and develop new noise reduction technologies, NASA in partnership with the FAA and the U.S. aerospace industry began a comprehensive program of aircraft noise reduction studies in 1992. These efforts were undertaken as part of the Advanced Subsonic Technology Noise Reduction Program and included both airframe and engine noise reduction research. Specifically, the engine noise reduction element called for $6 \mathrm{EPNdB}$ (Effective Perceived Noise $\mathrm{dB}$ ) reduction in the level of the engine system source noise relative to 1992 technology by the end of the last decade [3].

The engine noise element of the Advanced Subsonic Technology (AST) program included work on reducing both the fan and jet associated noise. The fan noise reduction portion itself was comprised of research in such areas as low-noise fan stage design, swept and leaned outlet guide vanes, active noise control, fan flow management, scarfed inlets, and advanced liners. In this paper we shall summarize these efforts and provide representative results. One notable exception is that we will not touch upon the acoustic liners which saw significant development under the AST program. This is an extensive area deserving of a separate review. Furthermore, since this review will focus on the AST work exclusively, it will also not include the research that was conducted outside of the purview of the AST program or that which was carried out in Europe or Japan during the same time period.

In what follows, the various noise reduction techniques will be listed in no particular order. In each case, a description of the method and its underlying principles will be presented. Where final assessments have been completed, a discussion of the relevant results, issues and conclusions will also be presented. Highlights from several efforts that were initiated under the AST engine noise reduction program but have not yet been fully assessed will also be included. The paper will conclude with a summary of current accomplishments and a few thoughts on future work.

\section{FAN NOISE REDUCTION TECHNIQUES}

\section{Advanced Ducted Propulsor}

Incorporating all of the proven fan noise reduction technologies of the time, Pratt and Whitney designed and built [4] a scale model fan stage known as the Advanced Ducted Propulsor (ADP), shown in Fig. 2, to demonstrate the feasibility of a propulsion system capable of meeting the AST noise reduction goal of 6 EPNdB.

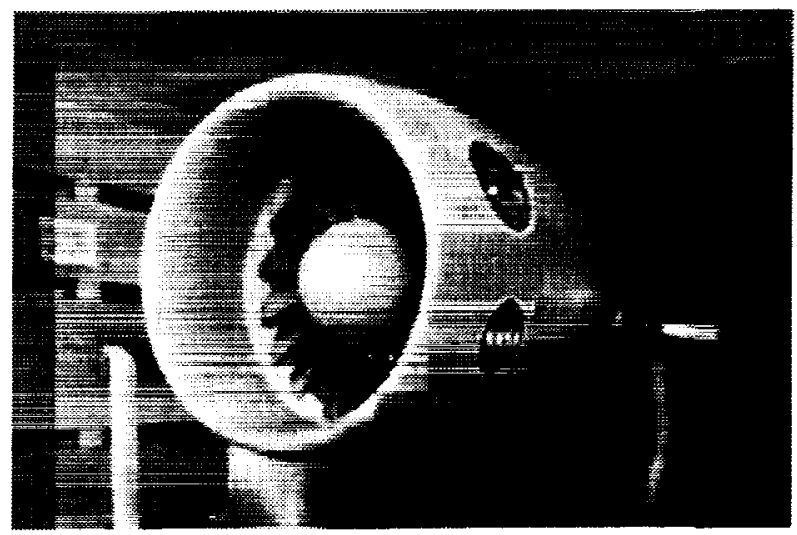

Figure 2. The Advanced Ducted Propulsor fan. Pictured is one of the 22" variants of the concept called Fan 1 shown installed in the NASA 9' $\times 15^{\prime}$ wind tunnel.

The ADP, which is built around a low tip-speed ${ }^{\dagger}$ variable-pitch fan, features large rotor-stator spacing and cut-off vane counts for both the bypass and core stators. The design also takes advantage of advanced liners in the inlet, mid-stage and exhaust sections of the fan duct to further mitigate the noise (see Fig. 3). While finalized system noise studies are not yet available, results from a number of NASA wind tunnel tests (see, for example, Refs. 5 and 6) indicate that the ADP is likely to fulfill its original design goal of meeting or exceeding the AST engine noise reduction target. Of course, the ADP represents a departure from the conventional cycle design and it remains to be seen whether it will be embraced by the industry.

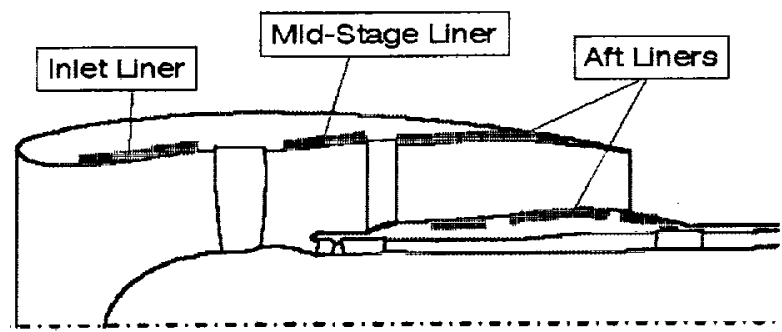

Figure 3. Acoustic liner locations inside the ADP fan duct.

${ }^{\dagger}$ Estimates based on the $\left(V_{\text {tip }}\right)^{8}$ rule suggest substantial noise benefits from lowering the fan tip speed significantly. 


\section{Outlet Guide Vane Sweep and Lean}

One of the great success stories of the AST engine noise reduction program has to be the proof that guide vane sweep and lean ${ }^{\ddagger}$ is an effective means of reducing fan noise. Starting in the early ' 70 s, several studies had hinted at the potential acoustic benefits of stator vane sweep and lean for reducing fan tone noise [7-11], but it wasn't until the AST program that the effectiveness of vane sweep and lean was convincingly demonstrated.

In a NASA/Allison wind tunnel test [12], farfield radiated noise levels produced by four aerodynamically equivalent outlet guide vane (OGV) configurations [13] were measured. The configurations included: a radial OGV (see Fig. 4a), the radial OGV but with increased rotor-stator axial spacing (see Fig. 4b), a 30degree swept OGV (see Fig. 4c), and a combination 30-degree swept and 30-degree leaned OGV (see Fig. 4d). The radial stator, representing the standard OGV design practice, served as the baseline against which the acoustic performance of the swept and leaned stator could be compared. The radial stator in the "aft" position was included to isolate noise reductions due to increased spacing that are realized when sweep is introduced, and the swept-only stator was included in an attempt to separate the sweep effects from those due to lean.

The test showed significant tone noise reductions with a swept and leaned OGV as illustrated by the 2BPF directivity results shown in Fig. 5. In this plot the noise benefits (i.e., tone level attenuations) are plotted relative to the radial OGV noise levels (a positive number is benefit) at both the approach and takeoff conditions. The swept and leaned stator shows significant noise benefits for all angles with reductions on the order of $5 \mathrm{~dB}$ in the inlet quadrant and over $10 \mathrm{~dB}$ in the exhaust quadrant at both conditions. On an EPNdB basis the results are equally impressive (see Fig. 6) showing more than 3 EPNdB noise reductions over the entire range of fan tip speeds for the swept and leaned OGV compared with the radial OGV in its nominal (forward) position.

The test results also indicate that the swept and leaned stator is quieter even when compared with the radial stator in the aft position. This suggests that the effectiveness of sweep and lean is not solely due to the additional viscous wake decay that is realized through the increased rotor-stator spacing for the swept and leaned stator as compared with the radial stator in its

\footnotetext{
\$ Sweep is the axial and lean the circumferential displacement of the vane leading edge from its radial position.
}
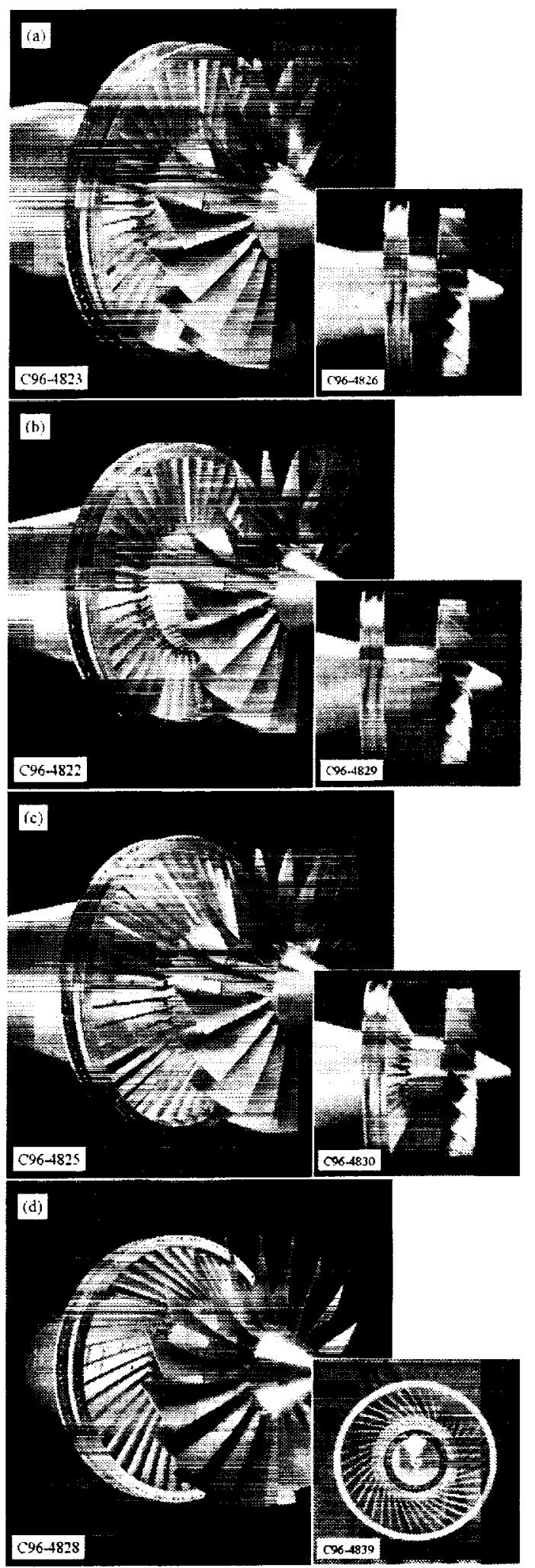

Figure 4. Photographs of partially assembled fan stages showing the four stator packs used in the sweep and lean study. (a) Baseline radial stator, (b) radial stator in aft position, (c) swept stator, and (d) swept and leaned stator. 

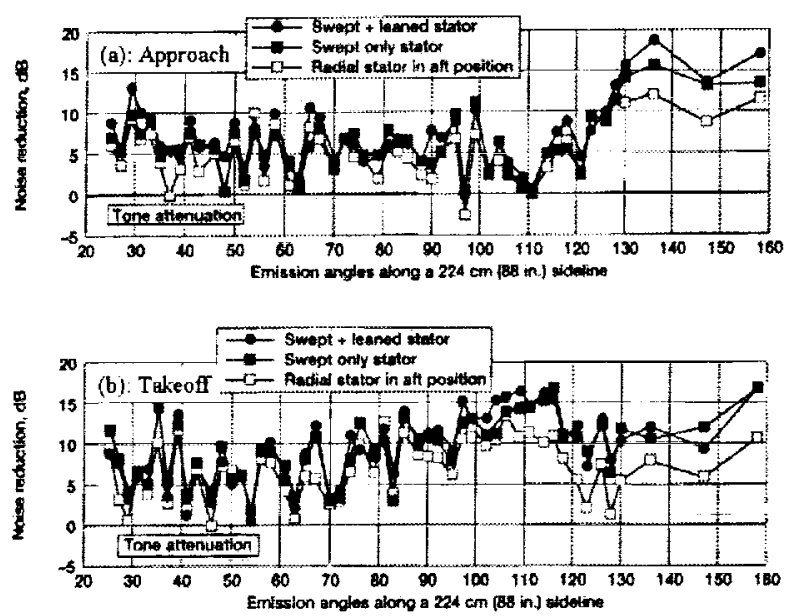

Figure 5. 2BPF sideline directivities showing noise reductions relative to the baseline stator (radial OGV in its nominal forward position). Benefits shown for (a) approach condition and (b) for takeoff condition. Figure reproduced from Ref. 12.

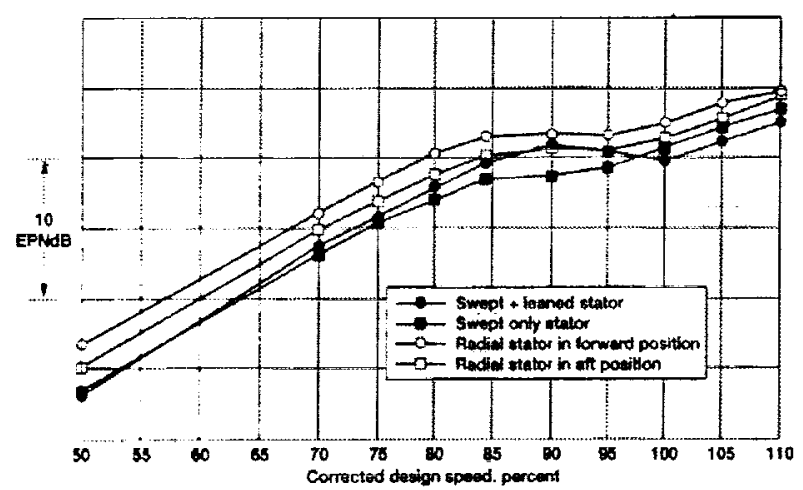

Figure 6. Sideline EPNL for fictitious twin-engine aircraft and flight path. Maximum relative noise levels on a $2000 \mathrm{ft}$ sideline are shown. Figure reproduced from Rer. 12.

forward position. Part of the noise benefit is due to the additional variation that occurs in the phase of the incident wake along the vane span due to the introduction of sweep and/or lean. More spanwise phase variation of the wake means more noise cancellation that can occur between the contributions from different locations along the vane span resulting in less interaction noise. Viewed in terms of the kinematics of wakes in relation to vanes, the noise benefits come from having more wakes intersecting a single vane with sweep and lean than without [14]. As shown in Fig. 7, there are more wake-vane intersections for the swept and leaned stator compared with the radial one.

One unexpected result was the apparent acoustic advantage of the swept-only stator over the swept and leaned stator for some fan tip speeds (say, $70 \%$ to $95 \%$ ). A theoretical design study [15] had indicated that the combination of sweep and lean was more effective than sweep alone. Analysis of the aerodynamic performance of the OGVs showed that the swept and leaned stator had somewhat higher aerodynamic losses than had been anticipated. This suggests that an improved aerodynamic design would have probably realized the full acoustic benefits of the swept and leaned stator. Nevertheless, the test did in fact prove the potential for significant noise reductions through the use of vane sweep and lean.
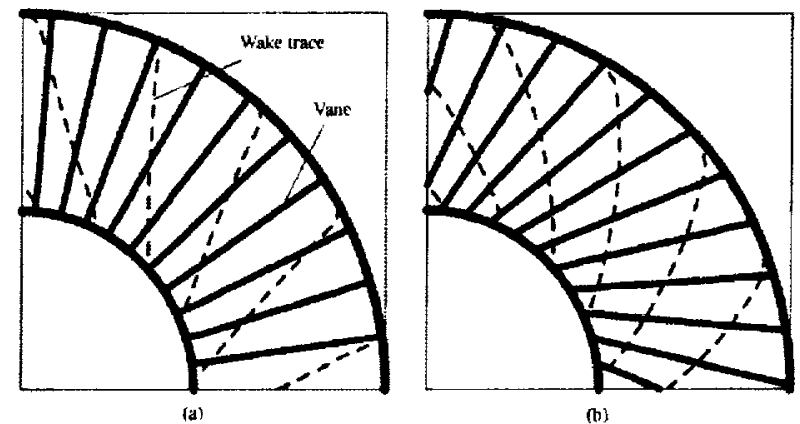

Figure 7. Schematic of the kinematic relationship between fan wakes and stator vanes. On the left, the picture depicts a typical relationship for a radial stator and on the right, for a swept and leaned stator. There are more wake/vane intersections for the swept and leaned stator. Figure reproduced from Ref. 14.

\section{Active Noise Control}

Motivated by the idea that a given acoustic field can be cancelled by another acoustic field of equal amplitude but opposite phase, a number of studies were carried out to determine the feasibility of active control of fan noise ${ }^{\S}$. Owing to the complicated nature of the noise field inside a fan duct, all of these "firstgeneration" techniques were aimed at canceling only fan noise with well-defined modal qualities. For this reason a dedicated active noise control fan (ANCF) rig was designed and built [17] as the testbed for assessing these techniques. The 4-foot diameter fan, shown in Fig. 8, has the unique capability for generating specific rotor-stator interaction mode or modes" at frequencies similar to those produced by large turbofan engines. At the same time, the rig can also accommodate a wide variety of active noise control systems. Despite their variety, however, each of the active noise control $\S$ An early theoretical system study [16] indicated that active
control could reduce fan noise by up to 2 EPNdB.

** These are the classical duct modes distinguished by their circumferential (or spinning) order $m$ and radial index $n$. 


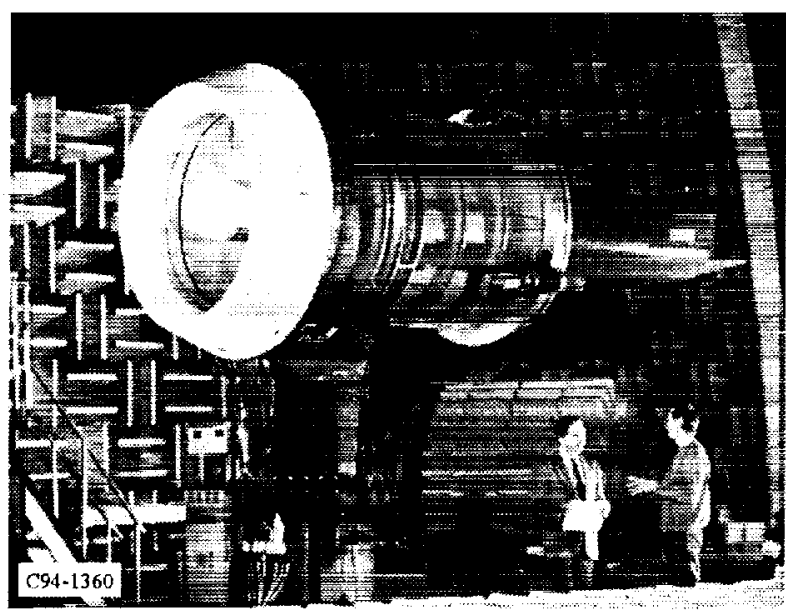

Figure 8. The NASA Glenn Active Control Fan rig was the testbed for most of the active noise control experiments conducted under the AST fan noise reduction program.

concepts tested was composed of three basic elements: (1) an "actuator" array to produce the canceling acoustic field, (2) an error sensor (e.g., microphone) array to monitor the level of cancellation, and (3) a control algorithm to analyze the output from the sensor array and synthesize the appropriate input for the actuator array in a continuous self-correcting loop.

The actuator array was generally comprised of an arrangement of resonant-type drivers or conventional electromagnetic drivers (i.e., speakers). The particular arrangement of the drivers used was predicated on: (1) the number of spinning modes that had to be cancelled simultaneously, and (2) on whether local control (i.e., inlet or exhaust noise cancellation) or global control (i.e., simultaneous inlet and exhaust noise cancellation) was desired. Depending on the particular concept, there were single or multiple actuator rings in the inlet duct upstream of the fan $[18,19]$, or in the exhaust duct downstream of the outlet guide vanes [20], or flanking the outlet guide vanes [21,22]. The drivers in this type of arrangements would be flush-mounted within the fan duct walls as shown by the examples in Figs. 9 and 10. A somewhat unique type of an arrangement was that involving actuators embedded within the vanes ${ }^{\dagger \dagger}$ themselves as shown in Fig. 11. This approach is described in detail in Ref. 25.

One so-called hybrid concept was also tested which utilized both active and passive elements. The active element was an arrangement of resonant-type drivers while the passive element was a conventional liner [26]. The working principle of this concept is

${ }^{\dagger \dagger}$ The initial concept study and development of candidate vane actuators for this work may be found in Refs. 23 and 24 .

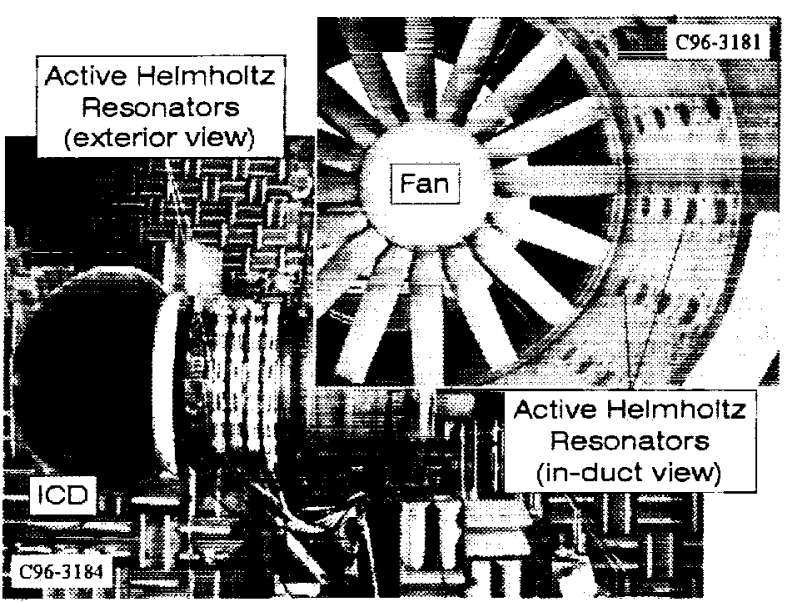

Figure 9. Active Helmholtz resonators drivers in a four-ring arrangement around the duct outer wall upstream of the fan in the inlet duct (see Ref. 18). View is from inlet duct looking downstream.

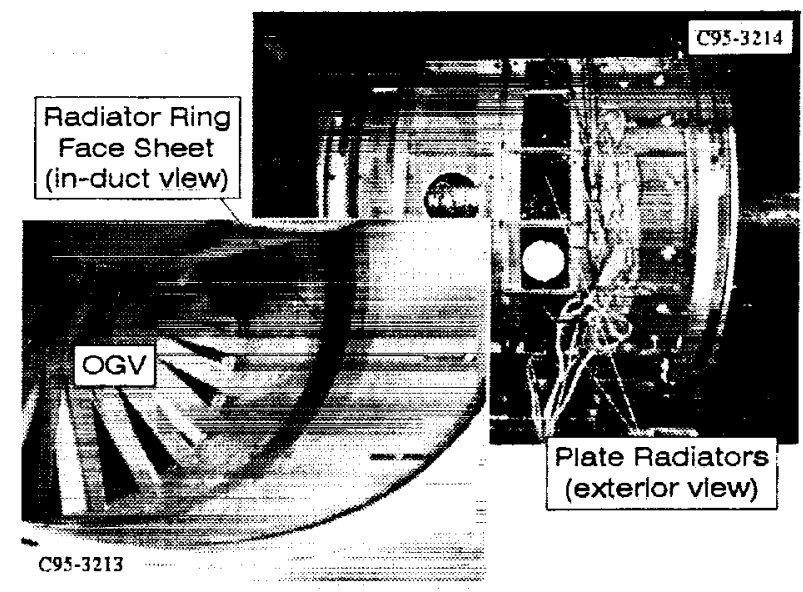

Figure 10. Plate radiator drivers in a ring arrangement around the outer wall of the fan duct. The location is downstream of the OGV in the exhaust duct (see Ref. 20). View is from exhaust duct looking upstream.

schematically depicted in Fig. 12. An optimized uniform (single-segment) liner (Fig. 12a) provides some attenuation commensurate with the orientation of the incident acoustic wave shown by the arrow. In a tandem two-segment liner arrangement (Fig. 12b) the first segment not only attenuates some of the incident wave, it also redirects the remaining portion toward the wall so that the second segment can more effectively attenuate the remaining energy. So, for equal treatment length, the two-segment liner system is more effective than the uniform liner. The hybrid active-passive system (Fig. 12c) improves on this scheme by allowing the system to adapt to the changes in the orientation of the original incident wave caused by the changes in the engine operation ensuring that the benefits of the passive portion are always optimized. 


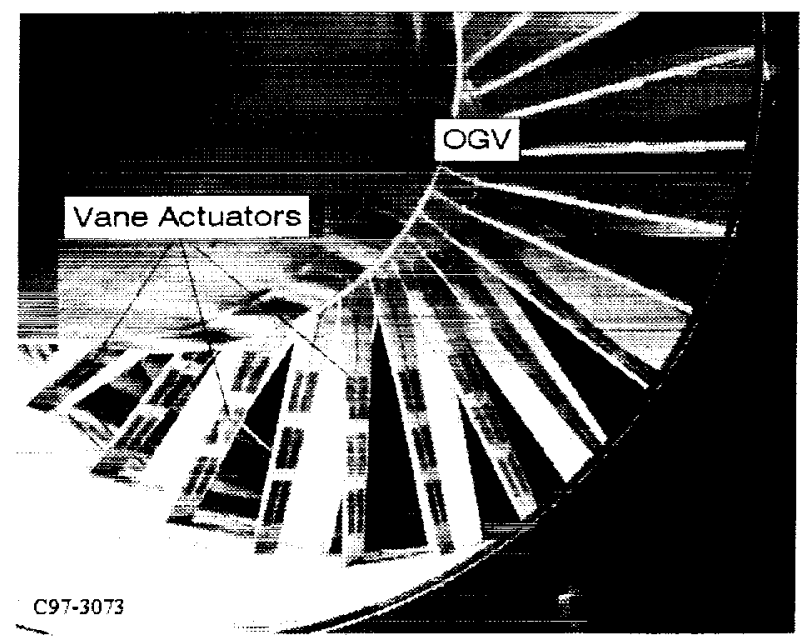

Figure 11. In this technique, the actuators are embedded within the profile of the stator vanes (see Ref. 25). View is from the exhaust duct looking upstream.

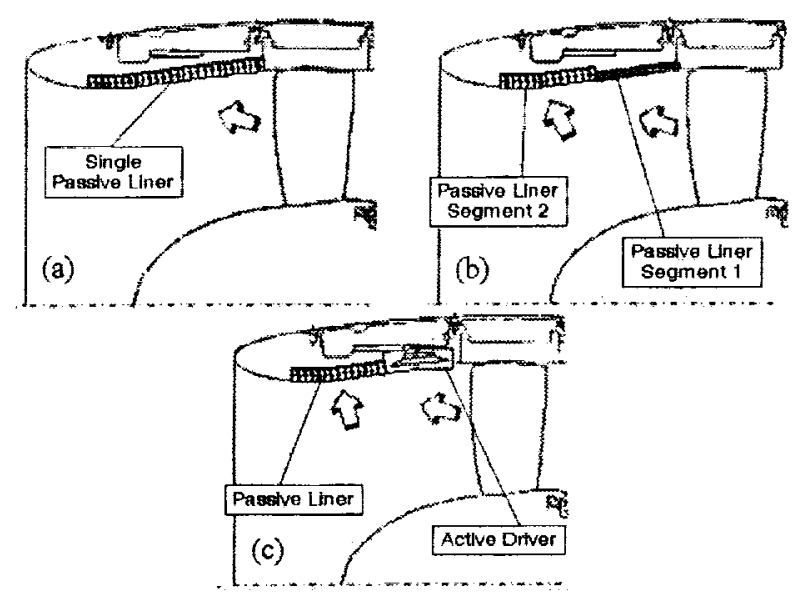

Figure 12. Conceptual development of the hybrid activepassive system. Performance improvements over a uniform liner (a) can be realized through the use of a tandem two-segment liner (b). The hybrid activepassive system (c) not only provides comparable performance to the two-segment liner, it also adds the capability to adapt to the changing engine environment. (See Ref, 26 for more details).

A summary of all of the AST active control tests conducted using the ANCF rig is shown in Table $1^{\ddagger \ddagger}$. The tests are organized in the order of increasing complexity as defined by the number of spinning modes that had to be controlled simultaneously. For each entry, the particular spinning mode(s) at which control was targeted and their relevant frequencies are tabulated. The last column indicates whether local

\footnotetext{
$¥$ There were other AST-sponsored active noise control tests that were carried out on scale model engines or other rigs. See, for example, Refs. 27, 28 and 29.
}

Table 1 - Summary of Active Noise Control Tests

\begin{tabular}{|c|c|c|c|c|}
\hline Test" & \begin{tabular}{|c|} 
\# Of \\
Modes
\end{tabular} & Spinning Mode(s) & Freq. & Dir. \\
\hline $1^{(20)}$ & 1 & $(6,0)$ & 2BPF & Ex. \\
\hline \multirow{2}{*}{$2^{(18)}$} & 1 & $(2,0)$ & $1 \mathrm{BPF}$ & \multirow{2}{*}{ In. } \\
\hline & 2 & $(4,0),(4,1)$ & $2 \mathrm{BPF}$ & \\
\hline $3^{(26)}$ & 2 & $(4,0),(4,1)$ & 2BPF & In. \\
\hline $4^{(19)}$ & 3 & $(1,0),(1,1),(1,2)$ & 2BPF & In. \\
\hline \multirow[t]{2}{*}{$5^{(21)}$} & \multirow{2}{*}{4} & $(4,0),(4,1)$ & \multirow{2}{*}{ 2BPF } & \multirow{2}{*}{ In. + Ex. } \\
\hline & & $(4,0),(4,1)$ & & \\
\hline \multirow{2}{*}{$6^{(25)}$} & \multirow[t]{2}{*}{4} & $(4,0),(4,1)$ & \multirow{2}{*}{$2 \mathrm{BPF}$} & \multirow{2}{*}{ In. + Ex. } \\
\hline & & $(4,0),(4,1)$ & & \\
\hline \multirow{3}{*}{$7 \mathrm{a}^{122 t}$} & \multirow{3}{*}{4} & $(2,0),(2,1)$ & \multirow{3}{*}{ 2BPF } & $\ln / \mathrm{Ex}$ \\
\hline & & $(2,0),(2,1,(2,2)$ & & In. Ex. \\
\hline & & $(2,0),(2,1),(2,2),(2,3)$ & & In/Ex. \\
\hline $7 b^{(22)}$ & \multicolumn{4}{|c|}{ Same as 7a but with different control algorithm. } \\
\hline
\end{tabular}

* Indicates the Ref. source for the test.

control (inlet or exhaust) or global control (inlet and exhaust) was considered. In each case, control was applied over a range of fan speeds to assess the robustness of the system in adapting to the changes in the mode characteristics as a function of the fan rpm.

To varying degrees, every one of the active noise control tests demonstrated measurable reductions in the level of the targeted mode(s). An example of the results ${ }^{\S \S}$ from one of the earliest tests is shown in Fig. 13, which depicts the reduction in the level of exhaust duct acoustic power level (PWL), denoted by the shaded area, due to the application of active noise control. The reduction is clearly significant averaging around $18 \mathrm{~dB}$ over the range of fan speeds tested. In an attempt to provide a summary of all of the results, average total PWL reductions versus the number of targeted modes are plotted in Fig. 14. The average is over the range of fan speeds in each case and the total is the sum of the power levels in all targeted modes (in the inlet and/or exhaust ducts). While this may be somewhat of a crude metric with which to gauge the noise reductions via active noise control, it does nonetheless serve as an indication of the potential of the active control technology in its current stage of development. In plotting the results, distinction is made between the local control in the inlet only, local control in the exhaust only, and global control in both inlet and exhaust simultaneously. For each data point, a label identifies the corresponding test listed in Table 1. For the test number 7 , over the range of tip speeds tested there was an increase in the number of cut-on spinning

$\$ \S$ Detailed results from most of these tests were presented at a recent meeting on active noise control [30]. 


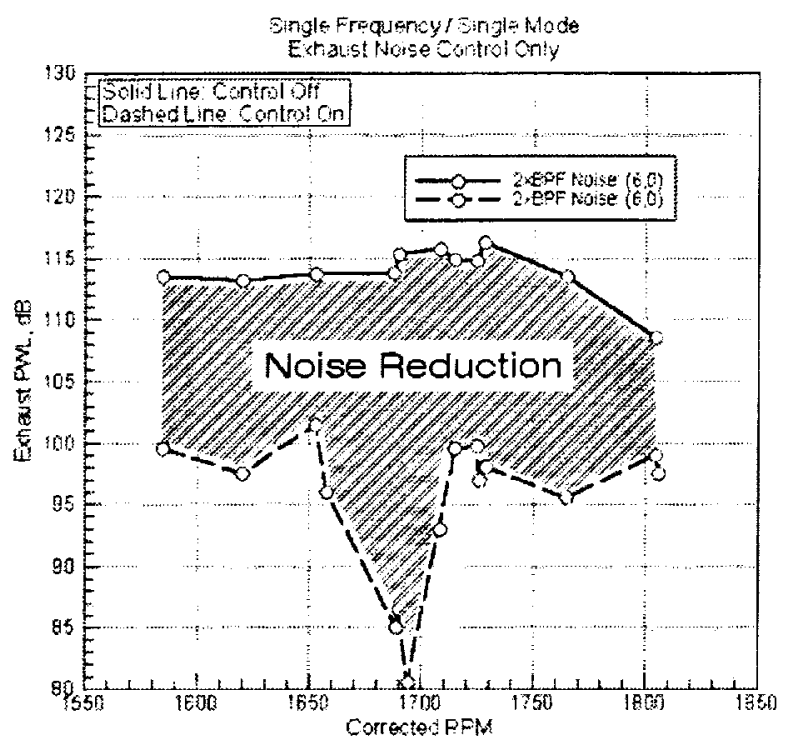

Figure 13. Reduction of fan duct mode power level due to active noise control over a typical range of fan speeds tested in the ANCF rig. (Results plotted from the data in Ref. 20).

modes from two to three and then to four in the inlet, and from two to three in the exhaust. Therefore, the reductions for each set of propagating modes are plotted separately.

The results as plotted in Fig. 14, indicate that there are significant noise reduction benefits from the use of active noise control, but that the magnitude of the noise benefits tends to diminish with increasing number of simultaneously controlled modes. While a

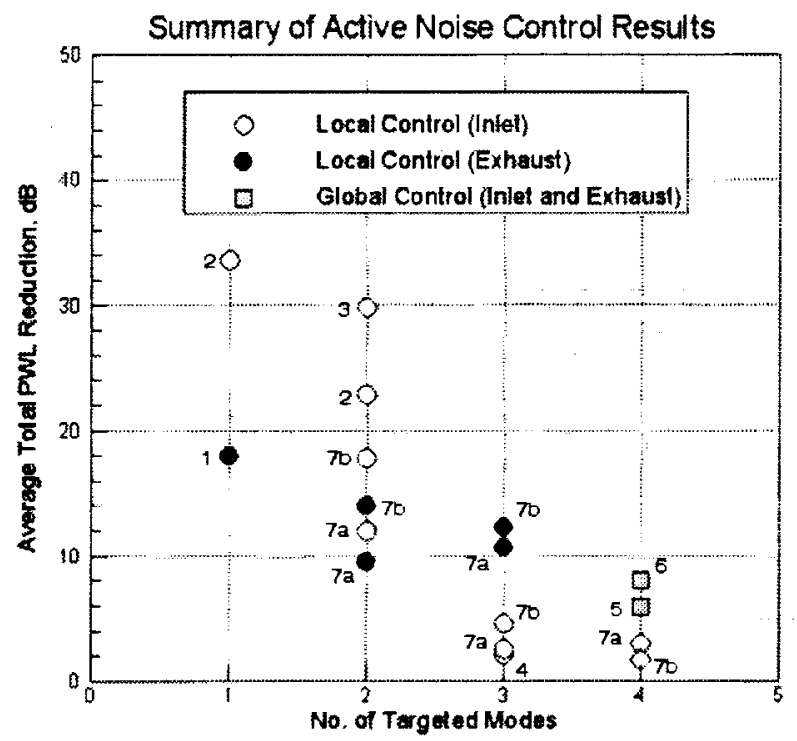

Figure 14. Fan noise level reductions achieved by active control. The labels refer to the test configurations listed in Table 1. detailed investigation of the reasons underlying this trend is outside of the scope of this review, one possible explanation may be as follows. Due to the nature of the rotor-stator generated modes, multiple duct modes always have a unique phase relationship with each other that depends on the axial location in the duct. Therefore, the level of control will be dependent on the accuracy with which the sensor array(s) can measure this phase relationship, and the accuracy with which actuator array(s) can synthesize it. Small errors in measurement and/or synthesis can therefore produce a canceling field that does not exactly match the target field resulting in less noise control (reduction). Since the complexity of the mode phase relationship increases with the number of modes, the control may be less effective when many modes exist compared with the situation when only one or two mode(s) exist.

Nevertheless, the important point to remember is that these tests clearly demonstrate the potential of active noise control as a means of reducing fan tone noise, particularly in circumstances when there are only one or two dominant modes to be controlled. A more general assessment regarding the utility of the active noise control techniques is not possible at this time since, to date, only one system analysis study ${ }^{* * *}$ has been carried out that incorporates the results from these tests.

\section{Fan Wake Management}

A novel approach for reducing fan tone noise involves the use of mass injection (or "blowing") at the blade trailing edge to reduce fan wake deficit. In principle, this should render the flow impinging on the downstream stator more uniform leading to lower levels of unsteady loading on the vanes and, hence, less rotor-stator interaction tone noise. Early experiments on flat plates [31] and 2D cascades [32] had established the feasibility of this approach, but issues remained in applying the method to realistic fan geometries. These issues were first tackled in a research effort carried out at MTT in the late 90's [33,34]. Building on a series of numerical and experimental investigations, a method was developed for designing a fan to study flow (and

\footnotetext{
**** That system study (see Ref. 22) predicted minimal benefits from the use of active noise control. However, this conclusion is colored by the particular choice made for the aircraft/engine combination used in the system study, which had de-emphasized the impact of tone noise reduction on the system flyover noise. An aircraft/engine combination for which tones are a more significant spectral component is likely to show more benefits from the application of active noise control.
} 
by implication) noise control in a realistic setting. The result was the fan shown in Fig. 15 whose blades each have a labyrinth of internal passages that start at the blade root, where they receive the flow supplied through the shaft, and terminate at a series of trailing edge ports, where the supplied fluid is discharged into the fan wake flow. Provisions were made to allow for spanwise tailoring of the injection profile.

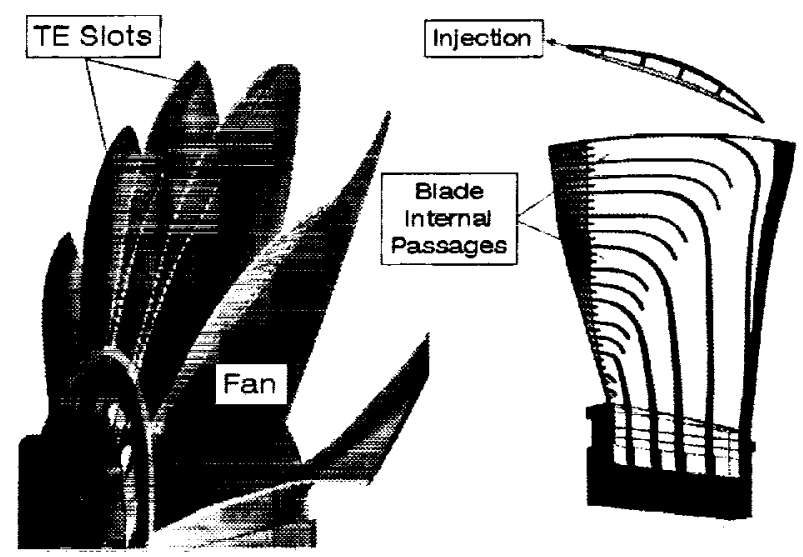

Figure 15. Close-up view of the MIT blown rotor (left) and a detailed view of the blade internal passages. (Reproduced from Ref. 34).

Combinations of several injection rates and profiles $^{\dagger \dagger \dagger}$ were tested using this fan. In each case, the flow downstream of the fan and the duct wall unsteady pressure levels were measured. A typical flow result is shown in Fig. 16. The trailing edge blowing has "filled in" the original wake (solid line) to produce a more uniform mean flow profile (dashed line). On a harmonic basis (see the inset), the trailing edge blowing has reduced the wake harmonic amplitudes by more than a factor of two for the first four harmonics.

A summary of the unsteady pressure results is shown in Fig. 17. Harmonic sound pressure levels (SPL), measured on the outer duct wall in the inlet and exhaust, are plotted for different injection rates. Depending on the rate of injection and the particular harmonic considered, wall SPL reductions as much as $9 \mathrm{~dB}$ were realized. However, sizeable increases (by as much as $6 \mathrm{~dB}$ ) were also observed in some cases. While these results clearly indicate the influence of wake management on the unsteady pressure field inside the duct, general conclusions regarding the noise benefits cannot be drawn. The reason is two fold. First, since the MTT facility is non-anechoic, the wall

\footnotetext{
${ }^{1+\dagger}$ Injection rate is defined as the percent of the fan through flow. The injection profile refers to the spanwise distribution of the discharge flow. Tip-biased and midspan-biased profiles were considered in the MIT experiment.
}

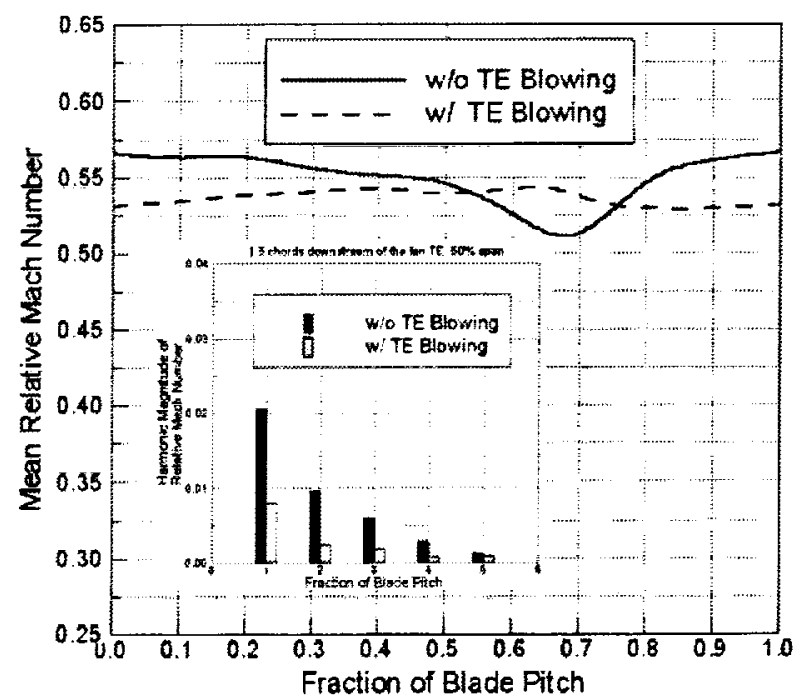

Figure 16. Typical mean relative flow profiles with and without fan trailing edge blowing. The measurements location is at $50 \%$ span and 1.5 chords downstream of the fan. Inset: Change in harmonic content of the wake due to trailing edge blowing. (Profiles reconstructed from Ref. 34 data).
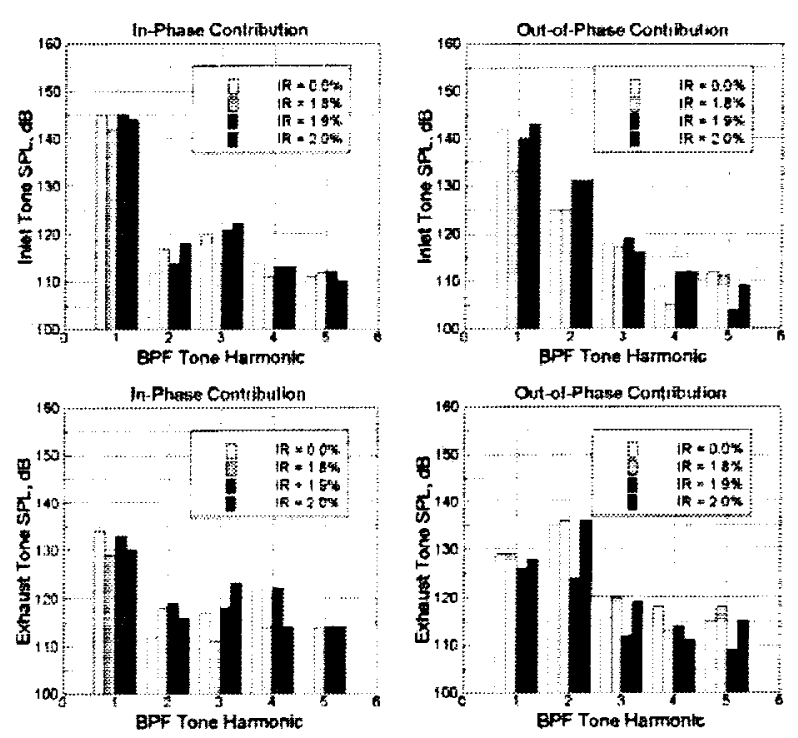

Figure 17. Measured wall tone sound pressure levels in the inlet and exhaust as a function of injection rates. The no-injection case is the baseline. In-phase and out-of-phase pressure results are plotted separately. (Based on data from Ref. 34).

unsteady pressure measurements can only be considered as rough estimates of the associated noise levels. Second, even in an anechoic environment, localized wall pressure measurements are not reliable indicators of the noise power levels in the duct. Nonetheless, the observed reductions in the amplitudes of the wake harmonics do indicate the potential for 
genuine noise power level reductions. Naturally, more work needs to be done to establish the full potential of the wake management technique for reducing rotorstator interaction tone noise.

\section{$\underline{\text { Scarfed Inlet }}$}

An old concept that was revisited during the AST noise reduction program is the use of a "scarfed" inlet. In theory, the asymmetric shape of a scarfed inlet lip with the lower portion protruding further forward than the upper portion (see Fig. 18), should shield the observer on the ground from the inlet noise by redirecting the noise upward. A number of studies in the early $80^{\circ}$ 's had established the potential benefits of scarfing, but had also indicated a possible problem. With a scarfed inlet, the asymmetry can introduce distortions in the flow ingested by the fan that can lead to extraneous noise that could potentially offset the shielding benefits of the scarfed inlet. However, recent advances in inlet and treatment design rekindled the interest in the concept. As a result a full-scale engine test on a Pratt and Whitney PW4098 engine was planned in the late 90 's which incorporated an advance low-noise scarfed inlet designed and built by Boeing [35]. The test was completed in 1999, but inlet aerodynamic and acoustic performance data has not yet been fully analyzed. Therefore, an assessment of the benefits of a scarfed inlet cannot be made at this time, although the preliminary results appear promising.

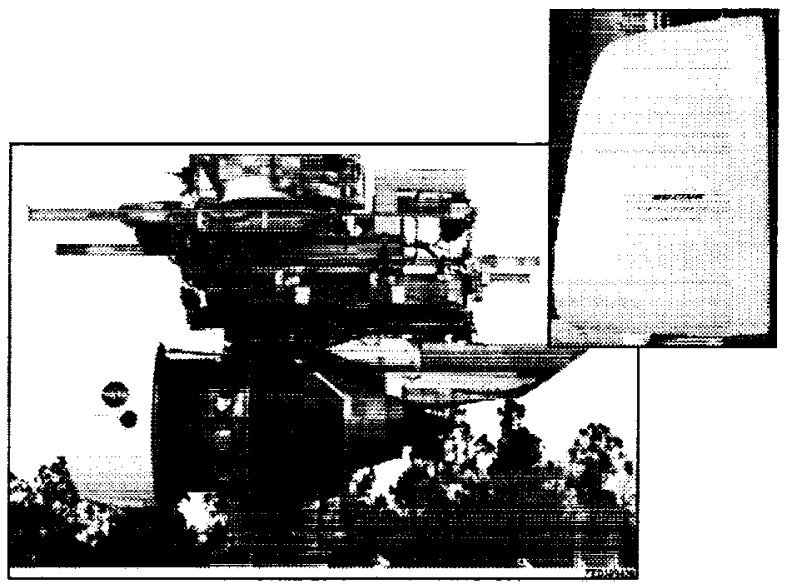

Figure 18. Boeing scarfed inlet installed on a Pratt \& Whitney 4098 engine. Photo reproduced from Ref. 36.

\section{SUMMARY AND DISCUSSION}

Fan noise reduction techniques developed as part of the Advanced Subsonic Technology Noise Reduction Program were reviewed. Highlights of developments in low-noise fan stage design, outlet guide vane sweep and lean, active noise control, fan wake management, and scarfed inlet were presented along with representative results and relevant conclusions (where available). For the most part, enabling technologies for achieving all or part of the 6 EPNdB engine source noise reduction goal have been demonstrated. Further work remains to be done in quantifying the benefits of some of the tested concepts such as the ADP fan, active noise control and scarfed inlet, but the outlook appears promising.

As for continuing and future work, there is a follow on NASA test planned for this year that is aimed at a careful quantification of the noise benefits from the trailing edge blowing. There has also been some additional testing of the outlet guide vane sweep and lean concept for fan stages with higher tip speeds than the original NASA/Allison fan. These more recent results should help provide a more general assessment of the acoustic benefits of sweep and lean. There has also been some theoretical work (not yet validated) involving optimized multi-segment fan aft duct liners that offer significant additional noise benefits over comparable single-segment liners.

Given the continuing emphasis on aircraft noise reduction, as indicated by NASA goals to provide technology to reduce noise by $10 \mathrm{~dB}$ by the year 2007 and $20 \mathrm{~dB}$ by the year 2022 , fan noise reduction is likely to remain in the forefront of future engine noise research.

\section{REFERENCES}

1. Owens, R.E., "Energy Efficient Engine Performance System - Aircraft Integration Evaluation," NASA/CR 159488, 1979.

2. Smith, M.J.T., Aircraft Noise, Cambridge University Press, 1989.

3. "Making Future Commercial Aircraft Quieter," NASA Facts, FS-1997-07-003-LeRC, or see www.lerc.nasa.gov/WWW/AST/noise.htm

4. Hobbs, D.H., Neubert, R.J., Malmborg, E.W., Philbrick, D.H., and Spear, D.A., "Low Noise Research Fan Stage Design," NASA/CR 195382, 1995.

5. Dittmar, J.H., Elliott, D.M., and Bock, L.A., "Some Acoustic Results from the Pratt and Whitney Advanced Ducted Propulsor - Fan 1," NASA/TM 1999-209049, 1999. 
6. Elliot, D.M. and Dittmar, J.H., "Some Acoustic Results from the Pratt and Whitney Advanced Ducted Propulsor Model," AIAA Paper 2000$0351,2000$.

7. Rao G.V.R., "Use of Leaning Vanes for Fan Noise Reduction," AIAA Paper 72-126, 1972.

8. Hayden, R.E., Bliss, D.B., Murray, B.S., Chandiramani, K.L., Smullin, J.I., and Schwaar, P.G., "Analysis and Design of a High Speed, Low Noise Aircraft Fan Incorporating Swept Leading Edge Rotor and Stator Blades," NASA/CR 135092, 1977.

9. Schulten, J.B.H.M., "Sound Generated by Rotor Wakes Interacting with a Leaned Vane Stator," AIAA Journal, no. 10, 1352-1358, 1982.

10. Envia, E. and Kerschen, E.J., "Noise Produced by the Interaction of a Rotor Wake with a Swept Stator Blade," ALAA Paper 84-2326, 1984.

11. Envia, E. and Kerschen, E.J., "Influence of Vane Sweep on Rotor-Stator Interaction Noise," $N A S A / C R$ 187052, 1990.

12. Woodward, R.P., Elliott, D.M., Hughes, C.E., and Berton, J.J., "Benefits of Swept and Leaned Stators for Fan Noise Reduction," AIAA Paper 990479, 1999.

13. Dalton, W.N., Elliott, D.B., and Nickols, K.L., "Design of a Low Speed Fan Stage," NASA/CR 1999-208682, 1999.

14. Envia, E. and Nallasamy, M., "Design Selection and Analysis of a Swept and Leaned Stator Concept," Journal of Sound and Vibration, Vol. 228, No. 4, December 1999.

15. Envia, E, Huff, D., and Morrison, C.R., "Analytical Assessment of Stator Sweep and Lean in Reducing Rotor-Stator Tone Noise," AIAA Paper 96-1791, May 1996.

16. Kraft, R.E., Janardan, B.A., Kontos, G.C., and Gliebe, P.R., "Active Control of Fan Noise Feasibility Study, Volume 1: Flyover System Noise Studies," NASA/CR 195392, 1994.

17. Heidelberg, L.J., Hall, D.G., Bridges, J.E., and Nallasamy, M., "A Unique Ducted Fan Test Bed for Active Noise Control and Aeroacoustics Research," NASA/TM 107213 and ALAA Paper 961740, 1996.
18. Walker, B.E., Hersh, A.S., Heidelberg, L.J., Sutliff, D.L., and Spencer, M., "Active Resonators for Control of Multiple Spinning Modes in an Axial Flow Fan Inlet," AIAA Paper 99-1853, 1999.

19. Smith, J.P., Burdisso, R.A., and Sutliff, D.L., "Active Control of Inlet Noise at the NASA Lewis Ducted Fan Facility," Virginia Polytechnic Institute and State University Report, 1997.

20. Pla, F.G., Hu, Z. and Sutliff, D.L., "Active Fan Noise Cancellation in the NASA Lewis Active Noise Control Fan Facility," NASA/CR 1985111, 1996.

21. Hersh, A.S., Walker, B.E., Leahy, R., Zhou, Z., and Heidelberg, L.J., "Active Control Dipole Sound Source Cancellation of Axial Fan RotorStator Interaction Noise," U.S. Patent applied for, April 1994.

22. Kraft, R.E., Hu, Z., Sommerfeldt, S., Walker, B.E., Hersh, A.S., Luo, H., Spencer, M., Hallman, D., Mitchell, C., and Sutliff, D.L., "Development and Demonstration of Active Noise Control Concepts," NASA/CR 2000-210037, 2000.

23. Kousen, K.A. and Verdon, J.M., "Active Control of Wake/Blade-Row Interaction Noise Through the Use of Blade Surface Actuators," NASA/CR 4556, 1993.

24. Simonich, J.C., "Actuator Feasibility Study for Active Control of Ducted Axial Fan Noise," NASA/CR 195412, 1995.

25. Curtis, A.R.D., "Active Control of Fan Noise by Vane Actuators, "NASA/CR 1999-209156, 1999.

26. Parente, C.A., Arcas, N., Walker, B.E., Hersh, A.S., and Rice, E.J., "Hybrid Active/Passive Jet Engine Noise Suppression System," NASA/CR 1999-208875, 1999.

27. Thomas, R.H., Burdisso, R.A., Fuller, C.R., and O'Brian, W.F., "Active Control of Fan Noise from a Turbofan Engine," AIAA Paper 93-0597, 1993.

28. Smith, J.P. and Burdisso, R.A., "Active Control of Inlet Noise from a Turbofan Engine Using Inlet Wavenumber Sensors," AIAA Paper 99-1808, 1999.

29. Burdisso, R.A. and Smith, P.J., "Control of Inlet Noise from a Turbofan Engine Using HerschelQuincke Waveguides," AIAA Paper 2000-1994, 2000. 
30. Heidelberg, L.J., "An Overview of the Fan Active Noise Control Effort at NASA Glenn," presented at the Joint Meeting of ASA, EAA \& DEGA, Berlin, Germany, March 19, 1999.

31. Naumann, R., "Control of the Wake from a Simulated Blade by Trailing Edge Blowing," Master's Thesis, Lehigh University, Bethlehem, PA, 1992.

32. Sell, J., "Cascading Testing to Assess the Effectiveness of Mass Addition/Removal Wake Management Strategies for Reduction of RotorStator Interaction Noise," Master's Thesis, MIT, Cambridge, MA, 1997.

33. Waitz, I.A., Brookfield, J.M., Sell, J., and Hayden, B., "Preliminary Assessment of Wake management Strategies for Reduction of Turbomachinery Fan Noise," AIAA J. of Propulsion and Power, Vol. 12, No. 5, 1996, pp. 958-966.
34. Brookfield, J.M., "Turbofan Rotor/Stator Interaction Noise Reduction Through Trailing Edge Blowing," Ph.D. Thesis, MIT, Cambridge, MA, 1998.

35. Raman, G., and McLaughlin, D.K. (Editors), "Highlights of Aeroacoustics Research in the U.S. - 1998," AIAA Paper 99-1915, 1999.

36. Huff, D.L., "Technology Development for Aircraft Noise Alleviation - Engine Noise Reduction Research," presentation made at the Hiller Aviation Museum, December 9, 2000. 
Public reporting burden for this collection of information is estimated to average 1 hour per response, including the time for reviewing instructions, searching existing data sources, gathering and maintaining the data needed, and completing and reviewing the collection of information. Send comments regarding this burden estimate or any other aspect of this

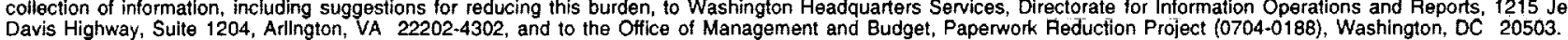

\begin{tabular}{|l|c|c|}
\hline 1. AGENCY USE ONLY (Leave blank) & $\begin{array}{c}\text { 2. REPORT DATE } \\
\text { February 2001 }\end{array}$ & $\begin{array}{r}\text { 3. REPORT TYPE AND DATES COVERED } \\
\text { Technical Memorandum }\end{array}$ \\
\hline
\end{tabular}

4. TITLE AND SUBTITLE

Fan Noise Reduction: An Overview
WU-781-30-11-00

8. PERFORMING ORGANIZATION REPORT NUMBER

E-12630

10. SPONSORINGMONITORING AGENCY REPORT NUMBER

NASA TM-2001-210699

AIAA-2001-0661

\section{SUPPLEMENTARY NOTES}

Prepared for the 39th Aerospace Sciences Meeting and Exhibit sponsored by the American Institute of Aeronautics and Astronautics, Reno, Nevada, January 8-11, 2001. Responsible person, Edmane Envia, organization code 5940, 216-433-8956.

12a. DISTRIBUTION/AVAILABILITY STATEMENT

12b. DISTRIBUTION CODE

Unclassified -Unlimited

Subject Category: 71

Distribution: Nonstandard

Available electronically at http//gltrs.grc.nasa.gov/GLTRS

This publication is available from the NASA Center for AeroSpace Information, 301-621-0390.

13. ABSTRACT (Maximum 200 words)

Fan noise reduction technologies developed as part of the engine noise reduction element of the Advanced Subsonic Technology Program are reviewed. Developments in low-noise fan stage design, swept and leaned outlet guide vanes, active noise control, fan flow management, and scarfed inlet are discussed. In each case, a description of the method is presented and, where available, representative results and general conclusions are discussed. The review concludes with a summary of the accomplishments of the AST-sponsored fan noise reduction research and a few thoughts on future work.

14. SUBJECT TERMS

Fan noise; Noise reduction

15. NUMBER OF PAGES

Fan noise; Noise reduction

17. SECURITY CLASSIFICATION OF REPORT

Unclassified

18. SECURITY CLASSIFICATION
OF THIS PAGE
Unclassified

Unclassified
19. SECURITY CLASSIFICATION OF ABSTRACT

Unclassified 